\title{
KAP STUDY \\ Knowledge, Attitude and Practices Regarding Cervical Cancer and Human Papilloma Virus (HPV) Vaccination
}

\author{
Meeshal Khan', Amara Zafar', Ramsha Muneer', Amna Siddiqui', Shuja Abdul Karim Khan', Arouba Zafar ${ }^{2}$ \\ 'Dow Medical College, Dow University of Health Sciences, Karachi, ${ }^{2}$ University of New South Wales, Sydney, Australia.
}

\begin{abstract}
Background: Cervical cancer remains the third most common cancer among women in Pakistan. Human Papilloma Virus is a major cause of cervical cancer. This study aimed to access knowledge regarding cervical cancer, awareness about the vaccine against Human Papilloma Virus (HPV), to compare the differences in the attitude of different groups of women and factors that may help to improve acceptance of the vaccine.
\end{abstract}

Methods: A cross-sectional study was carried out among 491 female students of Karachi. Participants were selected on random in the age group of 18 to 30; from different universities with the majority of the sample being medical students. Pearson Chi-squares and Mann Whitney $U$ tests were applied for the key statistical analysis and $p$-value $\leq 0.05$ was considered significant.

Results: In total of $343(69.9 \%)$ females were aware of the availability of the Human Papilloma Virus vaccine. Whereas, 60(19.3\%) of the females were vaccinated against Human Papilloma Virus while, $239(77.1 \%)$ of the females said that they intend to get vaccinated against the virus in the future. A significant relationship was found between the recommendation of HPV vaccine and the intention to get the vaccination $(p=0.002)$. Awareness of the HPV vaccine was more common among medical university students $(p \leq 0.05)$.

Conclusion: A large proportion of female undergraduate students have limited knowledge about HPV as a cause of cervical cancer and the HPV vaccine as the way to protect against it. Similarly, very few of the subjects are reported to be vaccinated against virus.

Keywords: HPV Vaccines; Human Papilloma Virus; Cervical Cancer.

\author{
Corresponding Author: \\ Dr. Amara Zafar \\ Dow Medical College, \\ Dow University of Health Sciences, \\ Karachi, Pakistan. \\ Email: amara.zafar@live.com \\ https://doi.org/10.36283/PJMD10-2/016
}

\section{INTRODUCTION}

The science of vaccinations was introduced over two centuries ago but has picked up momentum only recently'. Due to its relative newness, it has faced opposition and variable levels of acceptance $^{2}$. Developing countries have shown hesitancy regarding immunization programs with hesitancy in India being reported at 17\%, going up to $50 \%$ in Pakistan ${ }^{3}$.

Vaccination against Human Papilloma Virus (HPV) has been recommended for all females between the ages of 9-26 years since 2006 by the World Health Organization (WHO) ${ }^{4}$. HPV is a major cause of cervical cancer. HPV testing is therefore recommended as a screening tool for cervical cancer ${ }^{5}$, another research linked HPV to penile, anal, perianal and vulvar cancers ${ }^{6}$. Cervical cancer is one of the most common cancers in women around the world and of those that die from it, $85 \%$ belong to developing countries ${ }^{7}$. High-risk regions, with estimated age-standardized rates (ASR) over 30 per 100,000, include Eastern Africa, Melanesia, 
Southern and Middle Africa. Rates are lowest in Australia/New Zealand and Western Asia. In the United States of America, cervical cancer remains the second most common cause of cancer death in young women ${ }^{8}$. The significance of this aspect of healthcare can be gauged by the fact that cervical cancer remains the third most common cancer among women in Pakistan'. Cervical cancer is also among the three most common causes of cancer deaths in female ${ }^{10}$. Despite these statistics, there is still inadequate awareness and screening of HPV; often reasons for not getting tested or vaccinated against HPV is the false belief that people are not at risk, at other times it is general unawareness of the existence of vaccine, yet another reason is distrust in the safety and efficacy of the vaccine ${ }^{11}$.

With this background in mind, this survey was conducted to study the level of awareness and practices regarding HPV vaccination. It will also help us compare and contrast the differences in attitude of different groups of women and factors that may help improve acceptance of the vaccine. We have analyzed the information as well as the misconceptions that are harbored by these students enrolled in various universities and educational fields regarding cervical cancer, its susceptibility, prevention and vaccination. We have also studied the general attitude of the subjects towards the acceptance of HPV vaccinations offered, as well as the motives behind the reluctance obstructing its widespread use, and the general steps that can be taken as agreed upon by our participants to ensure a greater acceptance rate in our region. Therefore, our study aimed to bring into focus the existing level of awareness and knowledge of cervical cancer and HPV vaccination amongst undergraduate female students of Karachi.

\section{METHODS}

This cross-sectional study was conducted on the knowledge, awareness and attitude of 491 female university students in Karachi towards HPV vaccination. It was carried out from 1st May $22^{\text {nd }}$ July 2018. Participants were selected at random between the ages of 18 to 30 , from different universities: Dow University of Health Sciences (DUHS), Jinnah Sindh Medical University (JSMU), and Institute of Business Administration (IBA) with the majority of the sample being medical students due to majority of the data collectors based in medical universities in Karachi. Permission was taken from the head of the institutes for conducting the study. A structured questionnaire was designed. Informed written consent was taken from all participants before administering the questionnaire. The sample size was calculated in OpenEpi software sample size calculator with a $95 \%$ confidence interval and a
$5 \%$ margin of error.

The questionnaire was comprised of four parts. The first part included questions on demographic data. The second part consisted of knowledge about cervical cancer and HPV vaccine as well as the source of their knowledge. We also inquired about their knowledge regarding the availability of the vaccine and recommendations regarding the vaccine. In the third part, attitudes regarding getting vaccinated and their reservations were asked. In the final and fourth sections, they were asked about their practices regarding the vaccine.

IBM Statistical Package for the Social Sciences (IBM SPSS Statistics for Windows, Version 23.0 Armonk; New York) was used to analyze the data and tables were constructed using Microsoft Excel 2016. For the primary statistical analysis, Chi-squared and Mann-Whitney $U$ tests were applied. Results were presented as frequencies, a percentage with $p$-value $\leq 0.05$ was considered significant.

\section{RESULTS}

A total of $n=491$ university females' students were enrolled in the study. A majority $466(94.9 \%)$ of the study population was single. The mean age of the participants was (mean \pm S.D.) $21.58 \pm 1.98$ and $86.8 \%$ of the study population's family income was more than Rs 50,000 a month. Around four-fifths $403(82.1 \%)$ of the females were enrolled in medical and $88(17.9 \%)$ in non-medical universities. A majority 471 (95.9\%) of the females were doing bachelors and $20(4.1 \%)$ of them were doing post-graduation. Almost three-quarters 343(69.9\%) of the females in our sample were aware of the availability of the HPV vaccine. Regarding the source of their knowledge about the availability of the vaccine, $37.3 \%$ of females attributed health care workers as their source of knowledge, $13.7 \%$ said that relatives and friends were their sources of information, $26.2 \%$ said it was mass media and $22.8 \%$ gave credit to other sources. In our study population, $8.4 \%$ of females were sexually active, and $60(19.3 \%)$ of females were vaccinated against HPV.

About three-quarters (72.3\%) of the females believe that males should be vaccinated against the virus. Less than half (42\%) females believed that the HPV vaccine protects against penile cancer while $84.8 \%$ believed it to provide protection against the contraction of HPV infection thus prevention of infecting of the sexual partner. When asked $14.9 \%$ of females believed that they are very likely to contract HPV while $56.4 \%$ thought it was very unlikely and $28.7 \%$ said that they are never likely to contract HPV. A majority $(94.1 \%)$ of the females said that they think the vaccine helps prevent cervical cancer. When asked about the prevalence of 
cervical cancer $44.4 \%$ correctly identified it as the 3rd-4th most common cancer among women in Pakistan and $65.8 \%$ of females correctly identified the 9-25 age group as the vaccination recipient.

Comparing the knowledge and attitude (Table 1) towards the HPV vaccine with their intention to get the vaccination done. Less than three-quarters $239(77.1 \%)$ of the females said that they intend to get vaccinated. No significant relation was found between the awareness of risk factors of cervical cancer to get the vaccination done $(p=0.663)$. A significant relationship was found between the recommendation of HPV vaccine and the intention to get vaccination done $(p=0.002)$. Of the 310 females to be vaccinated about $20 \%$ were recommended the HPV vaccine while $80 \%$ were never recommended the vaccine by anyone. Among those who were recommended the HPV vaccine, health care professionals; doctors and nurses recommended $73.9 \%$. Of the 148 females with no intention to get vaccinated, 60(19.3\%) were recommended the vaccine. A majority of the females who were sexually active had the intention to get vaccination done ( $p$ value $=0.029$ ).

Table 1: Knowledge regarding cervical cancer and attitude towards HPV vaccination.

\begin{tabular}{|c|c|c|c|}
\hline Participants Characteristics & $\begin{array}{c}\text { Intention to get } \\
\text { vaccinated } \\
\text { n (\%) } \\
\end{array}$ & $\begin{array}{c}\text { No intention to get } \\
\text { vaccinated } \\
n(\%) \\
\end{array}$ & p-Value \\
\hline Awareness of risk factors of cervical cancer & $218 / 310(70.3)$ & $107 / 148(72.3)$ & \multirow{2}{*}{0.663} \\
\hline Unaware of risk factors & $92 / 310(29.7)$ & $41 / 148(27.7)$ & \\
\hline Recommended HPV vaccine & $60 / 310(19.3)$ & $12 / 148(8.2)$ & \multirow{2}{*}{0.002} \\
\hline No recommendation for HPV vaccine & $250 / 310(80.7)$ & $136 / 148(91.8)$ & \\
\hline Sexually active & $31 / 310(10.0)$ & $6 / 148(4.1)$ & \multirow{2}{*}{0.029} \\
\hline Sexually inactive & $279 / 310(90.0)$ & $142 / 148(95.9)$ & \\
\hline $\begin{array}{l}\text { Seek consultations for cervical cancer and } \\
\text { vaccination programs }\end{array}$ & 239/310 (77.1) & $68 / 148(45.9)$ & \multirow{2}{*}{$<0.05$} \\
\hline $\begin{array}{l}\text { Refusal to checkups for cervical cancer and } \\
\text { vaccination }\end{array}$ & $71 / 310(22.9)$ & $80 / 148(54.1)$ & \\
\hline
\end{tabular}

Females who were likely to get a consult from a doctor for cervical cancer and vaccination were more likely to be vaccinated ( $p$-value <0.05). The belief that the vaccine is helpful in the prevention of cervical cancer was found to have no link with the intention to be vaccinated ( $p$ value $=0.070$ ). Of the 148 people with no intention to be vaccinated about $80 \%$ said they would get vaccinated if the government conducted awareness programs ( $p$-value <0.05) and provided vaccines at subsidized rates or free of cost ( $p$-value< 0.05 ). Many females (83.8\%) who had no intention to be vaccinated said they would do so if it was recommended to them by a health care worker ( $p$-value<0.05). When asked about the reasons for not intending to get vaccinated, $2.6 \%$ said their religion/ethnicity did not allow it, $15.0 \%$ said they doubted the safety and efficacy of the vaccine, $47.1 \%$ said they were not at risk of HPV vaccine hence did not have to get vaccinated, $1.3 \%$ said it was expensive, $2.6 \%$ said their parent/spouse did not approve of the vaccine and $3.3 \%$ said the vaccine was not available at the local clinic.
Participants were asked for factors that might encourage them to get vaccinated of which $35.7 \%$ of females said the availability of free vaccines would encourage them to get vaccinated while $31.8 \%$ said family members getting vaccinated might motivate them. A quarter of females (25.5\%) said family members suffering from the disease might be a motivating factor for them to get vaccinated and $62.9 \%$ believed that awareness regarding the increased prevalence and mortality rates associated with cervical cancer might motivate them to get the vaccination done.

Figure 1 demonstrates the knowledge about the risk factors of cervical cancer. Of the 342 females who said they know the risk factors of cervical cancer, $80.4 \%$ of females identified having multiple sex partners as a risk factor, $81.3 \%$ of the participants identified HPV as a risk factor for cervical cancer, $28.9 \%$ homosexuality, $67.4 \%$ STD, $52.6 \%$ early first intercourse, $34.8 \%$ not using condoms and $48.3 \%$ immunodeficiency. Participants were allowed to choose multiple options. 


\section{Risk Factors Knowledge}

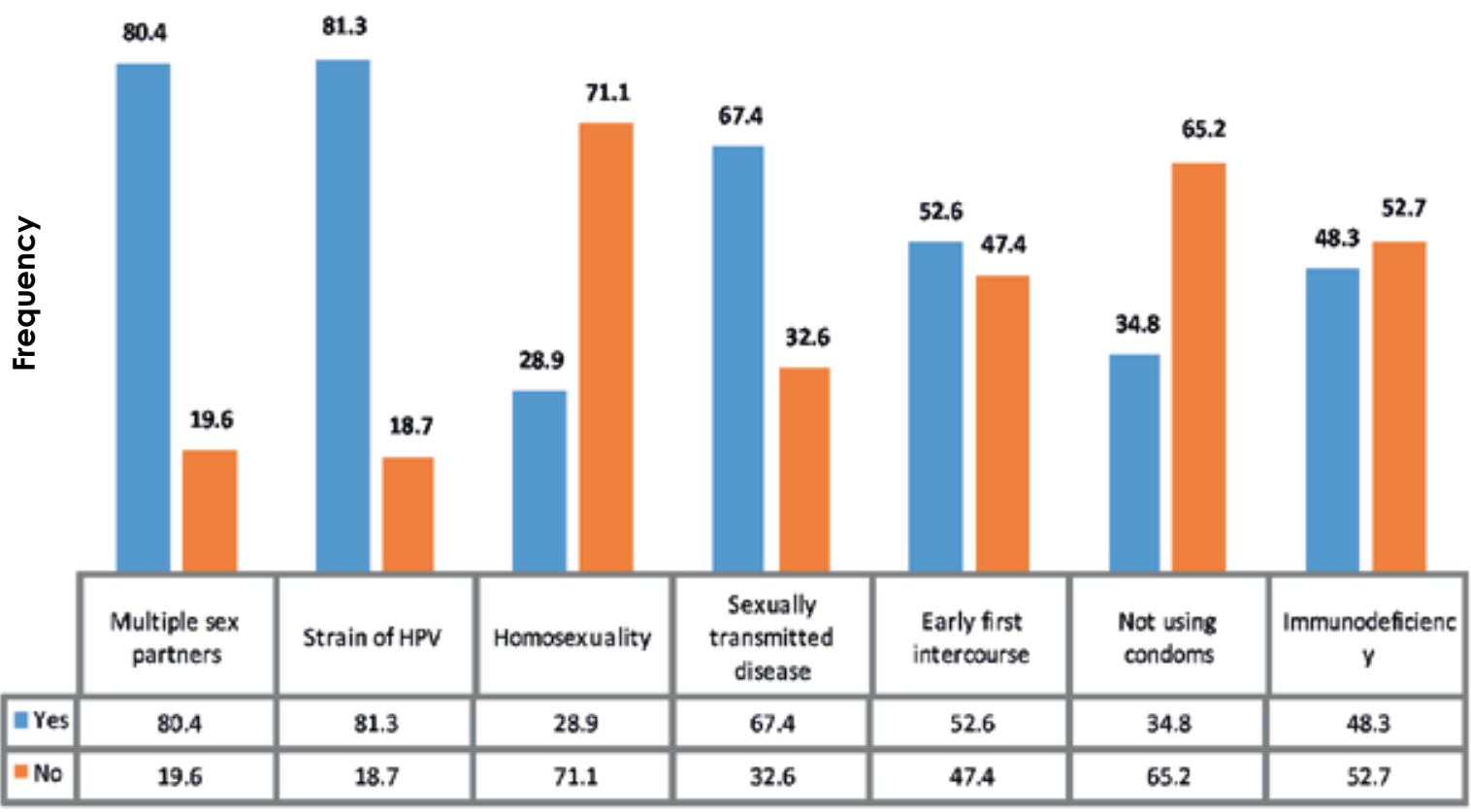

\section{Risk Factors}

\section{Figure 1: Knowledge about the risk factors of cervical cancer.}

Table 2 compares the awareness of the availability of HPV vaccine with different factors. About 343 $(70 \%)$ females were aware of the availability of the HPV vaccine. There was a significant relationship of age with the awareness of the HPV vaccine availability $(p=0.010)$. No significant relationship was found about the awareness of HPV vaccine availability with marital status, socioeconomic status and education level $(p=0.121,0.906$ and 0.139 respectively). Awareness of the HPV vaccine was more common among medical university students $(p<0.05)$. No relation was found between awareness of the availability of HPV vaccine and sexual activity $(p=0.195)$.

Table 2: Awareness of the availability of Human Papilloma Virus (HPV) vaccine.

\begin{tabular}{|c|c|c|c|}
\hline Participants Features & $\begin{array}{c}\text { Awareness on HPV } \\
\text { vaccine availability } \\
n(\%)\end{array}$ & $\begin{array}{c}\text { Unaware of HPV } \\
\text { vaccine availability } \\
\text { n (\%) }\end{array}$ & $p$-Value \\
\hline Medical University & $303(88.3)$ & $100(67.5)$ & \multirow{2}{*}{$<0.05$} \\
\hline Non-medical University & $40(11.6)$ & $48(32.4)$ & \\
\hline Recommended HPV vaccine & $80(23.3)$ & $10(6.7)$ & \multirow{2}{*}{$<0.05$} \\
\hline No recommended HPV vaccine & $263(76.6)$ & $138(93.2)$ & \\
\hline Intention to get vaccinated & $226(70.8)$ & $84(60.4)$ & \multirow{2}{*}{0.028} \\
\hline No intention to get vaccinated & $93(29.1)$ & $55(39.5)$ & \\
\hline
\end{tabular}

Towards the end of the questionnaire, participants were asked if after knowing about the availability of the HPV vaccine, they were likely to talk to their family about it to which $75.4 \%$ agreed. More than half $(67.4 \%)$ of the females agreed to likely consult a doctor to get more information and a check-up for cervical cancer and vaccination. Of the $32.6 \%$ females who said they would not get a consult, $2.3 \%$ said that they think it is a sin to discuss issues related to genitalia, $5.7 \%$ said talking about genital issues is a taboo in society, $17.1 \%$ said they feel embarrassed discussing it, $46.9 \%$ think it is insignificant to be discussed while $23.4 \%$ females picked others as the option. Participants were allowed to choose multiple options.

\section{DISCUSSION}

Cervical cancer remains a global burden in the field of health care and oncology despite having a 
clear-cut source of origin: the human Papilloma virus $^{12}$. Alongside other minor causes, HPV infection has persisted as the main culprit behind cervical cancer over the years. Cervical cancer remains the most common cancer in women in Eastern and Middle Africa to this date ${ }^{13}$. In Pakistan specifically, the incidence rate of cervical cancer is $4.1 \%{ }^{14}$.

In this study out of a total of 491 female undergraduate students in Karachi, only 343(69.9\%) were aware of the availability of the HPV vaccine. More prominent is the fact that in this study, only 60(19.3\%) reported being vaccinated against HPV. Consistent with our finding, in another study conducted in Karachi, only 13(1.3\%) of total 1038 respondents reported being vaccinated against HPV, while only $19.3 \%$ were aware of the vaccine ${ }^{15}$. According to the study conducted among university students in Pakistan by Khan et al. $53 \%$ of subjects were unaware of the vaccine while $64 \%$ of subjects rejected the statement that the HPV vaccine can prevent cervical cancer ${ }^{16}$. In a study conducted among interns and nursing staff of a tertiary hospital in Pakistan, only 37/400(0.09\%) were aware of the HPV vaccine $^{17}$. In a country where cervical cancer remains the third most common cancer among women, these statistics appear to be of grave consequence, especially considering that in our study, the undergraduate female students belong to educated backgrounds with $86.8 \%$ of the subjects belonging to high socioeconomic status (>50,000 PKR monthly income) and $82.1 \%$ of them were enrolled in medical universities. Similarly, In Italy, $42.1 \%$ of participants knew that the vaccine could prevent cancer, while only $15.3 \%$ knew about the availability of the said vaccine ${ }^{18}$. Comparable data of low rates of successful vaccination status were found in studies conducted in Hong Kong where $82.6 \%$ of subjects knew about the HPV vaccine but only $47.2 \%$ had received it ${ }^{19}$, and in Singapore where only $9.8 \%$ of subjects had been vaccinated against HPV ${ }^{20}$.

Some encouraging statistics were also obtained, $325(70.96 \%)$ who were not vaccinated were aware of the risk factors for cervical cancer and $65.8 \%$ identified the correct susceptible age group. Also, $72.3 \%$ of the females correctly believed that males should also be vaccinated. A majority $(94.1 \%)$ of the females knew that HPV vaccination can prevent cervical cancer, but only $72 / 458$ (15.7\%) had ever been recommended HPV vaccination. According to Zaheer et al. only (51.3\%), (23.5\%), and (13.3\%), had sufficient knowledge about cervical cancer, HPV, and HPV as a cause behind cervical cancer, respectively compare later ${ }^{15}$. Our study, thus, indicates a relatively higher level of knowledge regarding the risk factors of cervical cancer, and the usage of HPV against it. Nevertheless, only $10.54 \%$ of people in our study could be labeled as well aware of all aspects of cervical cancer and HPV vaccine.
A positive aspect of our findings was the fact that $67.7 \%$ of the women in our study reported that they intend to be vaccinated in the future. This is consistent with other studies conducted in Italy, Finland, and Malaysia where $81.7 \%, 86 \%$, and $53.3 \%$ people respectively reported willingness towards getting vaccinated in the future ${ }^{18,21,22}$. In our study, of the 148 people with no intention to be vaccinated about $80 \%$ said they would be vaccinated if the government conducted awareness programs ( $p$-value $<0.05$ ) and provided vaccines at subsidized rates or free of cost ( $p$-value< 0.05). Similar findings were obtained in Kenya and Northern India were $94 \%$ and $99 \%$ people respectively agreed on getting vaccinated if the vaccine provided was of no to low cost ${ }^{23,24}$. Contrary to these findings, in a study conducted in Singapore, only $58.3 \%$ people intended to be vaccinated despite the fact that $88.4 \%$ believed the vaccine to be efficient. Similarly, Ismail et al. reported HPV vaccine acceptability to be as low as $38 \%$ in their study, and as low as $12 \%$ if asked to pay for themselves ${ }^{25}$.

Women who reported being sexually active were more likely to be vaccinated in the future ( $p$ value $=$ 0.029 ), as was the case with women who regularly attended check-ups and consultations ( $p$-val$v e=<0.05$ ). This relationship between active sexual status and vaccination intent and uptake is supported by several other studies ${ }^{26,27}$. Of those with no intent of vaccination, $83.8 \%$ agreed that they would be vaccinated if they were recommended to do so by a health care provider (HCP). $37.3 \%$ of the $69.9 \%$ of women, who were aware of the availability of the vaccine, cited HCPs as their source of information. All this data strongly suggests that healthcare workers have a huge role to play in increasing vaccine coverage among our masses. In a study conducted by Jain et al. $80 \%$ of non-vaccinated participants agreed on being vaccinated if their Health Care Provider recommended it. In another study, adolescents were 5 times more likely to get vaccinated if they got recommended by their doctors 28,29 .

The obstacles in more widespread coverage of this vaccination are multi-fold; lack of awareness, cultural taboos and social nuances, unavailable resources and nonexistent immunization programs pave a road of difficulties in the provision of a barrier against HPV contraction. When asked about factors that might motivate the overall population to be vaccinated, a majority of our participants agreed that greater awareness about prevalence and mortality rates of cervical cancer ${ }^{15}$. The data received from these educated, young and relatively privileged women cannot entirely represent a city as diverse as Karachi in its vastly variable economic and cultural aspects. Furthermore, the self-reported surveys cannot be accounted for effectively. Another limitation to consider is the fact that our study participants 
belonged to a specific age group (mean=21.58), while HPV vaccination is eligible for girls $11-26$ years of age. We also included a limited number of institutions, and this data may not be representative of the entire undergraduate population of Karachi.

Lack of recommendation by health care professionals and awareness programs are largely to blame for this and while pharmaceutical companies have begun campaigns to spread knowledge about cervical cancer and the HPV vaccine, the government and Non-Government Organizations (NGO) need to take a more active part in getting the vaccines to women at subsided rates. During this survey, pamphlets published by GSK Pakistan with essential information were handed out to each participant by the team after they were done filling the questionnaire.

\section{CONCLUSION}

The knowledge about Human Papilloma virus (HPV) vaccination among women in Karachi is low. Even among the women who know about the vaccine, the acceptance rate remains minimal due to the lack of awareness. While most women think the vaccine works, they deny being at risk of acquiring the infection. The burden of increasing acceptability lies upon healthcare authorities as well as the governing bodies to ensure that a greater proportion of the population should be immunized against HPV.

\section{ACKNOWLEDGEMENTS}

The authors would like to acknowledge the Dow University of Health Sciences, Karachi for facilitating the research.

\section{CONFLICT OF INTEREST}

The authors declare no conflict of interest.

\section{ETHICS APPROVAL}

The study was approved by the Ethics Committee of Dow University of Health Sciences, Karachi.

\section{PARTICIPANTS CONSENT}

Informed written consents were taken from all participants.

\section{AUTHORS' CONTRIBUTION}

All authors equally contributed in this research write-up.

\section{REFERENCES}

1. Tahamtan A, Charostad J, Hoseini Shokouh SJ, Barati M. An overview of history, evolution, and manu- facturing of various generations of vaccines. J Arch Mil Med. 2017;5(3): 1-7.

2. Hussain A, Ali S, Ahmed M, Hussain S. The anti-vaccination movement: a regression in modern medicine. Cureus. 2018;10(7):1-8.

3. Larson HJ, Schulz WS, Tucker JD, Smith DM. Measuring vaccine confidence: introducing a global vaccine confidence index. PLoS Curr. 2015;7. Available from: https://www.ncbi.nlm.nih.gov/pmc/articles/PMC4353663/

4. World Health Organization. Preparing for the introduction of HPV vaccines: policy and programme guidance for countries [Internet]. World Health Organization; 2006 [cited $2020 \mathrm{Dec} 18$ ]. Available from: h t t ps: / / apps. who.int/iris / b i t stream/handle/10665/69384/WHO_RHR_06.11 _eng.pdf

5. Sasaki $Y$, Iwanari $O$, Arakawa I, Moriya T, Mikami $Y$, lihara $K$, et al. Cervical cancer screening with human papillomavirus DNA and cytology in Japan. Int J Gynecol Cancer. 2017;27(3):523-529.

6. de Peder LD, da Silva CM, Boeira VL, Plewka J, Turkiewicz $M$, Consolaro $M E$, et al. Association between human papillomavirus and non-cervical genital cancers in Brazil: a systematic review and meta-analysis. Asian Pac J Cancer Prev. 2018;19(9): 2359-2371.

7. Chawla PC, Chawla AK, Shrivastava R, Shrivastava A, Chaudhary S. Situation analysis of existing facilities for screening, treatment and prevention of cervical cancer in hospitals/primary health centers of Delhi-NCR region, India. Asian Pac J Cancer Prev. 2014;15(13):5475-5482.

8. Siegel R, Naishadham D. Jemal A. Cancer statistics, 2013. CA Cancer J Clin. 2013;63:11-30.

9. Bhurgri Y, Bhurgri A, Nishter S, Ahmed A, Usman A, Pervez $S$, et al. Pakistan-country profile of cancer and cancer control 1995-2004. J Pak Med Assoc. 2006;56(3):124-130.

10. Imam SZ, Rehman F, Zeeshan MM, Maqsood B, Asrar S, Fatima N, et al. Perceptions and practices of a Pakistani population regarding cervical cancer screening. Asian Pac J Cancer Prev. 2008:9(1):42-44. 1 1. Zimet GD, Rosberger Z, Fisher WA, Perez S, Stupiansky NW. Beliefs, behaviours and HPV vaccine: correcting the myths and the misinformation. Prev Med. 2013;57(5):414-418.

12. Trim K, Nagji N, Elit L, Roy K. Parental knowledge, attitudes, and behaviours towards human papillomavirus vaccination for their children: a systematic review from 2001 to 2011. Obstet Gynecol Int. 2012;2012:1-12.

13. HR FJ, Bray F, Forman D, Mathers C, Parkin DM. Estimates of worldwide burden of cancer in 2008: GLOBOCAN 2008. Int J Cancer. 2010;127 (12):2893-2917.

14. Bhurgri Y. Karachi cancer registry data--implications for the national cancer control program of Pakistan. Asian Pac J Cancer Prev. 2004;5(1):77-82.

15. Zaheer R, Alam N, Hussain KC, Herekar AA, Nasir H, Bhutta SZ. Awareness about human papillomavirus as a cause of cervical cancer and its prevention in the 
undergraduate female students of Karachi. J Pak Med Assoc. 2017;67(1):27-32.

16. Khan TM, Buksh MA, Rehman IU, Saleem A. Knowledge, attitudes, and perception towards human papillomavirus among university students in Pakistan. Papillomavirus Res. 2016;2:122-127.

17. Ali SF, Ayub S, Manzoor NF, Azim S, Afif M, Akhtar N, et al. Knowledge and awareness about cervical cancer and its prevention amongst interns and nursing staff in tertiary care hospitals in Karachi, Pakistan. PLoS One. 2010;5(6):1-6.

18. Di Giuseppe G, Abbate R, Liguori G, Albano L, Angelillo IF. Human papillomavirus and vaccination: knowledge, attitudes, and behavioural intention in adolescents and young women in Italy. $\mathrm{Br} \mathrm{J}$ Cancer. 2008;99(2):225-229.

19. Leung JT, Law CK. Revisiting knowledge, attitudes and practice (KAP) on human papillomavirus (HPV) vaccination among female university students in Hong Kong. Hum Vaccin Immunother. 2018;14(4):924-930.

20. Zhuang QY, Wong RX, Chen WM, Guo XX. Knowledge, attitudes and practices regarding human papillomavirus vaccination among young women attending a tertiary institution in Singapore. Singapore Med J. 2016;57(6): 329-333.

21. Woodhall SC, Lehtinen $M$, Verho T, Huhtala $H$, Hokkanen M, Kosunen E. Anticipated acceptance of HPV vaccination at the baseline of implementation: a survey of parental and adolescent knowledge and attitudes in Finland. J Adolesc Health. 2007;40(5) :466-469.

22. Al-Naggar RA, Al-Jashamy K, Chen R. Perceptions and opinions regarding human papilloma virus vacci- nation among young women in Malaysia. Asian Pac J Cancer Prev. 2010;1 1 (6):1515-1521.

23. Rositch AF, Gatuguta A, Choi RY, Guthrie BL, Mackelprang RD, Bosire R, et al. Knowledge and acceptability of pap smears, self-sampling and HPV vaccination among adult women in Kenya. PLoS One. 2012;7(7):1-9.

24. Zutshi V, Dankher S, Malik A. Cervical cancer screening and prevention: An analysis of beliefs and predictors of knowledge, attitude and practice in Northern India. Indian J Gynecol Oncol. 2017;15 (4): $1-4$.

25. Ismail H, Rashid MN. The knowledge, attitudes and practices (KAP) regarding human papilloma virus (HPV) among women in Karachi, Pakistan. Am J Biomed Life Sci. 2017;5(4): 69-72.

26. Jones M, Cook R. Intent to receive an HPV vaccine among university men and women and implications for vaccine administration. J Am Coll Health. 2008;57 (1):23-32.

27. Gerend MA, Magloire ZF. Awareness, knowledge, and beliefs about human papillomavirus in a racially diverse sample of young adults. J Adolesc Health. 2008;42(3):237-242.

28. Jain N, Euler GL, Shefer A, Lu P, Yankey D, Markowitz L. Human papillomavirus (HPV) awareness and vaccination initiation among women in the United States, National Immunization Survey-Adult 2007. Prev Med. 2009;48(5):426-431.

29. Ylitalo KR, Lee $H$, Mehta NK. Health care provider recommendation, human papillomavirus vaccination, and race/ethnicity in the US National Immunization Survey. Am J Public Health. 2013;103(1):164-169. 